\title{
The Predictive Value of Pre-Operative Symptoms Including Upper Gastrointestinal Endoscopy Before Laparoscopic Cholecystectomy for Elective Symptomatic Cholecystolithiasis
}

\author{
Karmacharya A, ${ }^{1}$ Malla BR, ${ }^{1}$ Joshi HN, ${ }^{1}$ Gurung RB, ${ }^{2}$ Rajbhandari $\mathrm{M}^{3}$
}

\author{
${ }^{1}$ Department of Surgery \\ ${ }^{2}$ Department of Internal Medicine \\ ${ }^{3}$ Department of Pathology
}

Dhulikhel Hospital- Kathmandu University Hospital Kathmandu University School of medical Science

Dhulikhel Hospital, Kavre, Nepal

\section{Corresponding Author}

Avish Karmacharya

Department of Surgery

Dhulikhel Hospital- Kathmandu University Hospital Kathmandu University School of medical Science

Dhulikhel, Kavre, Nepal

E-Mail: avish_karmacharya@hotmail.com

\section{Citation}

Karmacharya A, Malla BR, Joshi HN, Gurung $\mathrm{RB}$, Rajbhandari M. The Predictive Value of Pre-Operative Symptoms Including Upper Gastrointestinal Endoscopy before Laparoscopic Cholecystectomy for Elective Symptomatic Cholecystolithiasis. Kathmandu Univ Med J 2013;44(4):300-304.

\section{ABSTRACT \\ Background}

It has always been a challenge to distinguish between upper gastrointestinal symptoms due to gall stones or any other causes. The persistence of abdominal symptoms even after cholecystectomy is highly discouraging for surgeons.

\section{Objective}

To evaluate the value of preoperative (UGE) as a routine investigative tool in patients with gall stone disease and to assess the outcome of cholecystectomy in patients with gallstones on preoperative abdominal symptoms.

\section{Methods}

This is a prospective study conducted on 96 cases at the Department of Surgery, Dhulikhel Hospital among ultrasonographically proven gall bladder stones irrespective of age and sex. After the examination, all the patients were subjected to UGE, and biopsy were obtained for histopathology if required. The statistical analysis were performed using spss version 16 .

\section{Results}

Out of total patients, $84(87.5 \%)$ were females and $12(12.5 \%)$ were males with a M: $F$ ratio of 1:7. Both the sexes were comparable in age groups. Out of total 96 patients, $53(55.2 \%)$ presented with typical pain and $43(44.8 \%)$ presented with atypical pain. All the patients were subjected to upper gastrointestinal endoscopy (UGE) and 53(55.2\%) had normal findings and $43(44.8 \%)$ had various lesions. Patients with typical pattern of pain had normal endoscopic findings and those with atypical pain had pathology in upper gastroendoscopy $(p<0.001)$. Serious pathology resulting to change of the planned treatment was found in three cases (3.12\%). Among them two had gastric carcinoma and one had active peptic ulcer disease. The relief rate after the cholecystectomy was significant in patients with typical pain than among those with atypical pain $(p<0.001)$. The commenest post cholecystectomy symptoms were heart burn (10\%), abdominal discomfort (9\%) and dyspepsia (7\%).

\section{Conclusion}

Presence of atypical pain in patients with gall stones is highly likely to have other coexisting upper gastrointestinal pathologies. Hence, upper gastrointestinal endoscopy prior to elective cholecystectomy in patients with gall stones can be clinically helpful.

\section{KEY WORDS}

Biliary colic, cholelithiasis, upper gastrointestinal endoscopy 


\section{INTRODUCTION}

Cholelithiasis is one of the commonest problems encountered in surgery. ${ }^{1}$ In Asia, the prevalence of gallstone disease is $5-10 \%$ of population especially among older individuals and females. ${ }^{1}$ In Western countries, the prevalence of gall stone disease ranges from approximately $7.9 \%$ in men and $16.6 \%$ in women. ${ }^{1}$ The third National health and nutritional Examination survey estimated that 6.3 million men and 14.2 million women aged 20 - 74 years have cholelithiasis in United States of America. ${ }^{2}$

There are multiple etiologies for gall stone including lithogenecity, decrease in motion of gall bladder, augmented gall bladder volume, obesity, number of pregnancies, post operative periods, family history, estrogen replacement therapy, serum lipids and decreased physical activity. ${ }^{3}$

The pain due to the obstructing stone that causes sudden expansion of the gall bladder is called "Biliary Colic". ${ }^{4}$ This typical pattern of pain occurs at right upper quadrant or epigastric region and lasts between 15 mins to several hours commonly after a fatty meal. When pain gradually disappears it leaves behind a dull ache usually with nausea and vomiting. As the supply is splanchnic nerve, pain radiates to back, right scapula or shoulder tip and occasionallly to back. Any other spectrum of symptoms that does not fit typical pain criteria is considered atypical and include any abdominal discomfort, dyspepsia, nausea, belching, heart burn, food intolerance, flatulence, vomiting, loss of appetite. ${ }^{5}$

Persistent post cholecystectomy pain have been reported in $20-30 \%$ of patients. ${ }^{6}$ The presence of such persistent pain is also called "post cholecystectomy syndrome". The relationship between such persistent pain and cholecystolithiasis is often unclear. Coexistence of concurrent upper gastrointestinal problems with gallstones may have attributed to the post cholecystectomy syndrome. There is always an immense challenge in the evaluation of patients with upper gastrointestinal symptoms, who have gallstones to decide whether the stones in gallbladder are the source of the symptoms or an incidental finding. Differentiating between these two situations is important, because the prevalence of both conditions is common in the general population. Thus, this study tries to seek the importance of UGE to ob the association between gastrointestinal symptoms with gallstones among patients attending the Kathmandu University Dhulikhel Hospital.

\section{METHOD}

This hospital based prospective study conducted in the Department of Surgery, Dhulikhel Hospital between July 2012 to November 2013. Institutional approval was taken for the study. Verbal and written informed consent was taken from each participant. The data collected from the patients included personal information, presenting signs and symptoms, investigations including ultrasonography,
UGE finding, biopsy reports if present, medications, surgery details, any post-operative complications and findings.

Inclusion criteria were gallstones identified by ultrasonographic evaluation and with symptoms (typical or atypical). Typical symptoms included biliary colic whereas atypical symptoms included abdominal discomfort, dyspepsia, nausea, belching, heart burn, food intolerance, flatulence, vomiting and loss of appetite. The included patients underwent UGE before elective cholecystectomy.

Patients with acute abdomen, whose general conditions were not stable and patients with complicated gallstones such as choledocholithiasis, obstructive jaundice, cholangitis, gall stone pancreatitis, cholecystoenteric fistula, gall bladder neoplasm, previous biliary/ pancreatic surgery were excluded from the study.

UGE examination was performed in the endoscopy room 1-2 days prior to operation. The presence of ulcer and inflammation of gastric mucous membrane were subjected to histopathological examination.

The clinical symptoms were categorized as typical or atypical based on the characters mentioned above. The endoscopic findings were divided as normal, inflammatory, erosions, ulcers and others including carcinomas. Similar categorizations were applied for histopathological findings as well. The patients were followed up postoperatively on $7^{\text {th }}, 14^{\text {th }}$ and $30^{\text {th }}$ days to evaluate the presence of any preoperative symptoms. All the data were entered in MS EXCEL and analyzed using spss 16 . Chi square test was used to see the association between pain type, gender and endoscopic findings.

\section{RESULT}

Ninety six patients were included in this study of which the age range between 25-64 years with the mean age of $43.1 \pm 12.1$ years for males and $20-75$ years with a mean age of 39.9 years \pm 13.2 years for females. 84(87.5\%) were females and $12(12.5 \%)$ were males. Overall Male to Female ratio was 1:7. Presence of gallstones was confirmed by ultrasonography and $60 \%$ of the patients had multiple stones (Table-1).

Table 1. Comparison between characteristics of patients and nature of pain.

\begin{tabular}{|lcc|} 
& Typical Pain & Atypical Pain \\
\hline Male/Female ratio & $1: 4.8$ & $1: 13$ \\
\hline Mean Age(years) & 39.72 & 41.02 \\
\hline
\end{tabular}

Fifty three (55.2\%) patients presented with typical pain and $43(44.8 \%)$ with atypical pain (Table-1). Among patients with typical pain $9(17 \%)$ were male and $44(83 \%)$ were females. Similarly, among atypical pain $3(7 \%)$ were males and $40(93 \%)$ were females.

During UGE 53(55.2\%) had normal findings and 43(54.8\%) 
had various upper gastrointestinal lesions. Patients with typical pain had no significant endoscopic findings. Patients with atypical pain had abnormal endoscopic findings and were subjected to biopsy in cases of erosion and ulcer. Endoscopic findings revealed gastritis in $30(31.2 \%)$, duodenitis $7(7.3 \%)$, erosion in $4(4.2 \%)$, ulcers 2(2.1\%). In histopathological report one case suspicious of erosion and one of ulcer in endoscopy were reported as malignancy histopathologically. The therapeutic approach was changed in $3(3.1 \%)$ who were diagnosed with ulcer and malignancy in pathological reports. Cholecystectomy was performed in 93(96.8\%) patients. All the patients with abnormal endoscopic findings were prescribed proton pump inhibitors and Helicobacter Pylori therapy following positive Helicobacter Pylori in biopsies (Table2).

Table 2. Comparison of UGE and histopathological findings.

\begin{tabular}{|lcc|}
\hline UGE findings & $\begin{array}{c}\text { Histopathological find- } \\
\text { ings }\end{array}$ \\
\hline No abnormality & $53(55.2 \%)$ & Not done \\
Gastritis & $30(31.2 \%)$ & Not done \\
\hline Duodenitis & $7(7.3 \%)$ & Not done \\
\hline Erosion & $4(4.2 \%)$ & $3(3.1 \%)$ \\
\hline Ulcer & $2(2.1 \%)$ & $1(1 \%)$ \\
\hline $\begin{array}{l}\text { Others (including } \\
\text { carcinoma) }\end{array}$ & 0 & $2(2.1 \%)$ \\
\hline
\end{tabular}

In all patients with typical pain complete relief of symptoms were observed within one week post- operatively. However, patients with atypical pain had persistence of symptoms. The persistence of symptoms overtime were heart burn $(42.5 \%)$, nausea $(85.7 \%)$, dyspepsia $(50 \%)$ and abdominal discomfort (50\%) on $7^{\text {th }}$ post operative day. The subsequent follow up of the patients with symptoms showed significant reduction on the $14^{\text {th }}$ and $30^{\text {th }}$ days with presence of heart burn (10\%), dyspepsia (6.25\%) and abdominal discomfort (9.4\%)(Table 3).

Table 3. Comparison of Symptoms Preoperatively and Post Operatively.

\begin{tabular}{|llllll|}
$\begin{array}{l}\text { Symp- } \\
\text { toms }\end{array}$ & $\begin{array}{l}\text { Pre } \\
\text { operative } \\
\text { symp- } \\
\text { toms } \\
\text { N }\end{array}$ & $\begin{array}{l}\text { Persis- } \\
\text { tence of } \\
\text { symptoms } \\
\text { Post-oper- } \\
\text { atively } \\
\text { (7th Day) }\end{array}$ & $\begin{array}{l}\text { Persis- } \\
\text { tence of } \\
\text { symp- } \\
\text { toms } \\
\text { Post-op- } \\
\text { eratively } \\
\text { (14th }\end{array}$ & $\begin{array}{l}\text { Persis- } \\
\text { tence of } \\
\text { symp- } \\
\text { toms } \\
\text { Post-op- } \\
\text { eratively } \\
\text { (1 month) }\end{array}$ & $\begin{array}{l}\text { Cure } \\
\text { Rate* } \\
\text { (\%) } \\
\text { after } \\
\text { one } \\
\text { month }\end{array}$ \\
\hline $\begin{array}{l}\text { Biliary } \\
\text { Colic }\end{array}$ & 53 & 0 & 0 & 0 & 100 \\
\hline $\begin{array}{l}\text { Heart } \\
\text { Burn }\end{array}$ & 40 & 17 & 10 & 4 & 90 \\
\hline $\begin{array}{l}\text { Nausea } \\
\text { Dyspepsia }\end{array}$ & 32 & 16 & 13 & 0 & 100 \\
\hline $\begin{array}{l}\text { Abdomi- } \\
\text { nal Dis- } \\
\text { comfort }\end{array}$ & 32 & 16 & 13 & 2 & $92.8 \%$ \\
\hline
\end{tabular}

*Cure rate is defined as a number of those with given symptoms preoperatively who do not have the symptoms postoperatively.
There was a significant association between the nature of pain and the UGE findings. Patients with a typical pain had some positive finding in UGE. Similarly, the cure rate was remarkable in those with typical pain and those with a typical pain required medical interventions (Table 4).

Table 4. Association Between Pain Type, Endoscopic Findings and Relief Rate.

\begin{tabular}{|c|c|c|}
\hline Pain Type & Endoscopic Findings & P value* \\
\hline Typical Pain (53) & Normal (53) & \multirow[t]{3}{*}{0.001} \\
\hline Atypical Pain(43) & Abnormal (43) & \\
\hline & re Rate in one week & \\
\hline Typical Pain( 53) & 53 & \multirow[t]{2}{*}{0.001} \\
\hline Atypical Pain (43) & 0 & \\
\hline
\end{tabular}

\section{DISCUSSION}

So far published study on the role of UGE prior to elective cholecytectomy is not documented in context of Nepal. According to the various studies, a wide variety of symptoms exhibited by patients with gallstones are sometimes not relieved by the removal of gallbladder. ${ }^{6,7}$

The symptoms of gallstones can be variable ranging from nonspecific to acute medical emergency. Eighty percent of patients with cholelithiasis are asymptomatic. ${ }^{8}$ Most studies shows generally, patients appear to be symptomatic at the rate of two and three percent. ${ }^{8}$ Among them two percent has an overall risk of biliary complications such as acute pancreatitis and acute choledocholithiasis and $0.02 \%$ have the risk of incidence of gallbladder cancer. ${ }^{9,10}$

Among symptomatic patients, half of the patients develop biliar colic within a year. ${ }^{11}$ Though biliary colic is specific for gallstones, most of the patients, however, present with other abdominal symptoms. ${ }^{11}$ Unfortunately, till date there is no current evidence that justify the correlation of any other abdominal symptoms beside biliary colic in the diagnosis of gall stones. When the patient present with nonspecific symptoms, the demonstration of gallstone by ultrasound scanning does not exclude the coexistence of other conditions that might be responsible for non specific symptoms as proven by the various studies. ${ }^{12,13}$

In the present study, age group of our patients ranged from 20-75 years with the mean age of 40.3 years. This is in contrast to other studies in Nepal, conducted by Shrestha et al and Maskey et al on gall stones and their compositions. ${ }^{14,15}$ In their studies, the commonest age group was below 30 years. The difference in age of presentation could be due to the location of the study. Since, the other two studies were conducted in Kathmandu where the people have much easier approach to the medical facilities than Dhulikhel. However, the age group of presentation in our study is consistent to other studies in India where the mean age at presentation was 40.6 years. ${ }^{16,17}$ The rate of gall stone formation after the age of 20 tends to increase with each decade. ${ }^{18,19}$ This is due to increase in the amount 
of cholesterol in bile which increases with age due to dyslipoprotenemia. ${ }^{18,19}$ This dyslipoproteinemia causes increase cholesterol excretion in bile. Similarly, there is also decrease in the synthesis of bile acids due to decrease function of the enzyme cholesterol 7 alpha-hydroxylase. Besides this there is also hemoperfusion of the gall bladder wall due to sclerotic changes along with age. ${ }^{18,19}$

In oue study, the disease showed higher prevalence among females (87.5\%) as compared to males (12.5\%). According, to a study by Cirillo, the etiology has been attributed to the role of female sex hormones. ${ }^{20} \mathrm{~A}$ study by Hulley et al has performed a research to equate the relation between estrogen receptors and cholesterol synthesis. ${ }^{21}$ The study emphasized on the fact that estrogen stimulate the release of HMG Co-A reductase which simultaneously increase the synthesis of cholesterol leading to increased chances of supersaturation. ${ }^{21}$ Similarly, progesterone hormone which inhibits the gall bladder contractility may also contribute to the stone formation by causing bile stasis. ${ }^{21}$

In our study we aimed to determine the association between the nature of pain (typical/ or atypical) with the preoperative UGE findings. Normal findings in these patients with typical pain reinforces the fact that patients with typical abdominal pain has less likelihood of presenting with coexisting upper gastrointestinal lesion as evidenced in other studies. ${ }^{22,23}$

In contrast patients with atypical abdominal pain had higher incidence of concomitant upper gastrointestinal lesions besides gallstones which would not have been diagnosed if UGE had not been performed pre operatively. In similar studies by Faisal et al and Mozafar et al found among $77.2 \%$ and $83 \%$ of patients with atypical pain had abnormal UGE findings. ${ }^{24,25}$ This establishes the importance of UGE prior to elective cholecystectomy especially with atypical pain. Thybusch et al found $50 \%$ of patients undergoing endoscopy prior to cholecystectomy had pathological findings in endoscopic examination and management plan changed in $8.3 \%$ of patients which is in contrast to our study where change of management was in $3.1 \% .{ }^{26}$ These findings are also corroborated by Rashid et.al who suggested the routine use of UGE helped to reduce the overall cholecystectomy rates with beneficial clinical and economical outcomes. ${ }^{27}$ This is comparable to the findings in our study where UGE was valuable in detecting the other gastrointestinal lesions and further enhancement of management by addition of proton pump blocker that significantly subsided the residual atypical symptoms. Although the evidence in favor of preoperative UGE is on rise, few studies suggest UGE has little effect on the post operative outcome. ${ }^{28}$ The evaluation of Al-Azawi et al compared a group of patients who underwent UGE before cholecystectomy and a group without UGE before the surgery. ${ }^{28}$ Their study showed the use of preoperative UGE had no significant benefit in decreasing the post operative residual abdominal pain. ${ }^{28}$
As revealed by our study, the advantage of detecting gastric cancer by UGE at an early stage cannot be ignored. There were two cases of gastric carcinoma in our study. Both of them were moderately differentiated adenocarcinoma Likewise, other gastric lesions mainly peptic ulcer may have been overlooked. Active peptic ulcer disease is associated with one of the largest number of complications during and after cholecystectomy. ${ }^{29}$ This includes active bleeding and perforation as a result of stress and unavoidable effect of anti-thrombotic prophylaxis. Thus, the patients with pathological diagnosis of ulcer are not subjected to surgery and prescribed anti-ulcer treatment. In one patient diagnosed as active ulcer, the treatment protocol was changed and operation was postponed. The operation was done after four weeks of anti-ulcer treatment of patients and repeat UGE revealing the healing of ulcer, Similarly, the strategy of the procedure was also revised for patients diagnosed with carcinoma as per the location and advancement of tumor. Similar change in the treatment modalities have been seen in various other studies following UGE. Sasoda et.al suggested among patients with asymptomatic gall stones, abdominal pain is most likely secondary to underlying peptic ulcer disease. ${ }^{29}$ In his study, UGE was peformed in 2800 patients the surgery was delayed in patients with ulcer and 16 patients had complete resolution of symptoms after medical treatment and cholecystectomy was not performed. ${ }^{29}$

Patients with typical pain had no residual tenderness after one week of operation and were relieved of biliary colic present pre-operatively. The rapid decrease in pain score among them within the first post operative week suggested that it was mainly due to the surgical trauma rather than the symptoms of gall stone disease. Whereas initial surgical follow up of remaining cases with atypical pain subjected to cholecystectomy had persistence of symptoms. However, follow up after one month showed remarkable decrease in the symptoms of these patients with $10 \%$ still complaining of heart burn and dyspepsia. A study in Pakistan among 197 patients revealed a complete relief of pain, vomiting and flatulence post surgically. ${ }^{30}$ However, food intolerance was relieved in only $92.5 \%$. A Scottish study by Luman et al showed out of 97 patients with cholelithiasis, nausea was relieved in $94 \%$ and food intolerance in $80 \% .{ }^{31}$ The persistent heart burn could be due to the exaggerated duodenogastric reflux or dysfunction of sphincter of oddi as mentioned in other studies. ${ }^{32,33}$ Likewise, the presence of dyspepsia in some are consistent in keeping with earlier records where it has been due to functional motility disturbances of gastrointestine referred as biliary dyskinesia. ${ }^{34,35}$

Thus, due to higher incidence of concurrent upper gastrointestinal problems in patients with gall stones and atypical abdominal pain UGE before elective cholecystectomy can highly influence the treatment management which in this group can be clinically helpful regarding postoperative outcomes. 


\section{CONCLUSION}

Our study confirms that certain symptoms associated with gallsones are not alleviated by cholecystectomy itself and requires further exploration including UGE. Thus, it is recommended to perform routine UGE prior to cholecystectomy as many gastrointestinal lesions may coexist which prevents the complete relief of the symptoms.

\section{REFERENCES}

1. Huang J, Chang CH, Wang JI, Kuo HK, Zin JW, Shan WY. Nationwide epidemiological study of several gallstone disease in Taiwan. BMC Gastroenterol. 2009;9:63.

2. Everhart JE, Kharre M, Hill M, Maver KR. Prevalence and ethnic differences in gallbladder diseases in the United States. Gastroenteroscopy. 1999;117:632-9.

3. Conte D, Fraquelli M, GiuntaM, Conti CB. Gall stones and Liver disease; an overview. J Gastrointestin Liver Dis. 2011;20:9-11.

4. Basselink MGM, Erpecum KJ. Biliary Colic is a valuable clinical descriptor for Biliary pain due to " uncomplicated" gallstone disease. J Gastrointest Sung. 2009;13( 9):1745-6.

5. Berger MY, Hartman TC, Vander VJJM, Bohnen A. Is biliary pain exclusively related to gall bladder stone ? A controlled prospective study. Br J Gen Pract. 2004;54(303): 574-9.

6. Murshid KR. The post cholecystectomy syndrome, a review. SGA 1996;2(3):124 -37.

7. Mehrvarz S, Fanaei SA, Ziaee SA. The role of laparascopic cholecystectomy in alleviating gastrointestinal symptoms. IJMMS 2010;2(5):153-7.

8. Patino JF, Quintero GA. Asymptomatic cholelithiasis revisited. World J Surg. 1998;22:1119-24.

9. Kottke TE, Feldman RD, Albert D. The risk ratio is insufficient for clinical decisions. The case of rophylactic cholecystectomy. Med Decis Making. 1984;4:177-94.

10. Khan JS, Ali Hassan I, Khan MM, Iqbal M. Frequency of Incidental Carcinoma Gall bladder in Laparascopic cholecystectomy. JRMC 2013;17(1): 36-8

11. Berger My, Vander VJJ, Lijmer JG, dekort H, Prins A, Bohnen AM. Abdominal symptoms; do they predict gallstones ? A systemic review. Scand J Gastroenterol. 2000;35(1):70-6.

12. Glambek I, Arnesjo B, Soreide O. Correlations between gallstones and abdominal symptoms in a random population, results from a screening study. Scand J Gastroenterol. 1989;24:277-281.

13. Jorgensen T. Abdominal symptoms and gallstone disease: an epidemiological investigation. Hepatology. 1989;9:856-60.

14. Shrestha HG, Bajracharya M. Incidence of Cholelithiasis and its correlation with cancer of gallbladder at TUTH. JNMA. 1991;21:264 $-7$.

15. Maskey CP, Shrestha MI, Sato Y. Gallstone in TUTH. JIOM. 1990;12: 45-54.

16. Nagaraj SK, Paul P, Kumar MK, Muninarayanapp S, Anantharamaiah $\mathrm{H}$. Risk factors and the biochemical Evaluation of Biliary Calculi in Rural Kolar, Karnataka, India: A Rural Perspective of an Urban Disease. JCDR. 2012;6(3):364-8.

17. Gaharwar A. Factors Favoring Cholelithiasis in North Indian Population. IOSR-PHR. 2013; 3(5): 1-3.

18. BergmanS, Sourial N, Vedel I, Hana WC, Fraser SA, Newman D. Gall stone disease in the elderly and older patients managed differently? Surg Endosc. 2011;25: 55-61.
19. Grigorieva IN. Major risk factors for cholelithiaisis. Rossiskiy Zhurnal Gastroenterologii Gepatologn, Koloproktologii .2007;6:17- 9.

20. Cirillo DJ, Wallace RB, Rodabough RJ. Effect of estrogen therapy on gall bladder disease. JAMA. 2005; 293: 330-9.

21. Hulley S, Grady D, Bush T. Randomized trial of estrogen plus progestin for secondary prevention of coronary heart disease in postmenopausal women. Heart and estrogen /progestin Replacement study(HERS). Research Group. JAMA. 1998;280:605-13.

22. Boryl L, Anderson IB, Bardram L, Christensen E, Sehested A, Kehlet $\mathrm{H}$ et.al. Preoperative prediction model of outcome after cholecystectomy for symptomatic gallstones. Scand J Gastroenterol. 1999;34(1):1144-52.

23. Velpen GCV, Shimi SM, Cuschieri A. Outcome after cholecystectomy for symptomatic gall stone disease and effect of surgical access Laparascopic Vs open approach. Gut 1993;34:1448-51.

24. Faisal A, Gadallah AN, Omar SA, Nagy MA. The role of upper Gastrointestinal Endoscopy in Prevention of Post - Cholecystectomy pain prior to the elective surgical therapy of chronic cholecystitis. Med J Cairo Uni. 2013; 81 (1): 289- 93.

25. Mozafer M, Sobhiyeh M, Heiba Tollahi $M$. Is esophagogastroduodenoscopy essential prior to the elective surgical therapy of symptomatic cholelithiasis ? Gastroenteroscopy and Hepatology from bed to Bench. 2010;3(2);77-82.

26. Thybusch A, Schaube H, Schweizer E, Gollnick D, Grimm H. Significant value and therapeutic implications of routine gastroscopy before cholecystectomy. J Chir. 1996;133(4);171-4.

27. Rashid F, Rashid N, Waraich N , Ahmed J, Iftikhar SY. Role of routine esophagogastroduodenoscopy before cholecystectomy. Int J Surg 2010; 8(3):236-8.

28. Al- Azawi D, Rayis A, Hehir D J. Esophagogastroduodenocopy prior to laparoscopic cholecystectomy. J Laparoendosc Adv Surg Tech A. 2006 ;16(6):593-7.

29. Sasoda K, Zurawinski W, Piecuch J. Gastroduodensocopy; a routine examination of 2800 patients before laparascopic cholecystectomy. Surg Endosc. 2005;19:1103-8.

30. Amir M, Zubair M. Influence of cholecystectomy on symptomatic choleclithiasis. Can all symptoms be in proved? RMJ. 2009;34:141-4.

31. Luman W, Nixon SJ, Mcintyre Intestinal metaplasia, Hamer-Hodges D, Wilson G. Incidence of persistent symptoms after laparoscopic cholecystectomy; a prospective study. Gut. 1996;39:863-6.

32. Tanaka M, Ikeda S, Nakayama F. Change in bile duct pressure responses after cholecystectomy. Gastroenterology. 1984;87:1154-9.

33. Thune A, Saccone GTP, Scicchitano JP, ToouliJ. Distension of the gall bladder inhibits sphincter of oddi motility in humans. Gut. 1991; 32:1448-51.

34. Walsh TN, Russell RCG. Cholecystectomy and gallbladder conservation. Br J surg. 1992;79:4-5

35. Stefanini P, Carbone M, Patrassi N, Loriga P, De Bernarddinis G, Negro P. Factors influencing the long term results of cholecystectomy. Surg Gynaecol Obstet. 1974;139:734-8. 